\title{
Autophagy plays an important role in stemness mediation and the novel dual function of EIG121 in both autophagy and stemness regulation of endometrial carcinoma JEC cells
}

\author{
XIAOMIN RAN, PING ZHOU and KEQIANG ZHANG \\ Department of Gynecologic Oncology, Hunan Cancer Hospital, The Affiliated Cancer Hospital of \\ Xiangya School of Medicine, Central South University, Changsha, Hunan 410013, P.R. China \\ Received February 7, 2017; Accepted May 16, 2017
}

DOI: $10.3892 /$ ijo.2017.4047

\begin{abstract}
Endometrial cancer (EC) is the third most common gynecologic malignancy in the world, and is considered a chemotherapy poor responding cancer. There are two underlying mechanisms on chemoresistance: the stemness of cancer stem cells (CSCs) and activation of pro-survival autophagy. It was found that autophagy is one of the main factors of cancer stem cell survival, multidrug resistance and maintenance of the homeostasis of cancer stem cells and normal cancer cells. However, the relationship between CSCs and autophagy of EC cells is still unknown. In this study, higher autophagy level was found in endometrial cancer stem cells (ECSCs) and stemness kept in line with autophagy in successive cultured JEC spheres. Autophagy inhibition decreased the properties of CSCs in JEC spheres and enhanced sensitivity of ECSCs to paclitaxel. Besides, it was found that EIG121 exerted dual functions in the regulation of autophagy and stemness not only in normal JEC cells but also JEC obtained CSCs. These findings could be useful for developing targeted therapies for endometrial carcinoma.
\end{abstract}

\section{Introduction}

Endometrial cancer (EC) is one of the common gynecologic malignancies which incidence is rapidly increasing all over the world $(1,2)$. Approximately $80 \%$ of endometrial cancers are diagnosed at an early stage, hysterectomy combined with

Correspondence to: Dr Ping Zhou, Department of Gynecologic Oncology (5), Hunan Cancer Hospital, The Affiliated Cancer Hospital of Xiangya School of Medicine, Central South University, 283 Tongzi Po Road, Yuelu, Changsha, Hunan 410013, P.R. China

E-mail: zhouping@hnszlyy.com; zprxm2017@sina.com

Abbreviations: CSCs, cancer stem cells; EC, endometrial cancer; ECSCs, endometrial cancer stem cells

Key words: endometrial cancer, cancer stem cells, autophagy, chemoresistance, EIG121 chemotherapy is the primary treatment for EC (3). Because of the hope for survival and pregnancy, prevention and treatment of endometrial cancer is of great importance. Chemotherapy is a main treatment strategy for EC but chemoresistance is a restrictive factor for its clinical outcome. Endometrial cancer is considered to be a chemotherapy poor responding cancer type. The effectiveness of conventional chemotherapy with platinum-derived compounds, doxorubicin, anthracyclines, and paclitaxel is only ranging from 25 to $57 \%$ (4). Therefore promoting chemosensitivity of endometrial carcinoma cells could lead to an improved clinical curative effect (5).

Chemoresistance is considered to be the main cause of the treatment failure in $>90 \%$ of metastatic tumors (6). Chemoresistance is due to two mechanisms, primary and acquired resistance (7). Tumors can be intrinsically resistant prior to chemotherapy, or acquired resistance during treatment by tumors which are initially sensitive to chemotherapy(6). Existence of cancer stem cells (CSCs) is thought to be one of the main reasons for resistance to chemotherapy and responsible for the clinical results. CSCs are recognized as a small proportion of cells among the tumor cell population which are capable of self-renewal, aberrant differentiation, and escape homeostasis (8). It has been demonstrated that CSCs stay quiescent and resist chemotherapy agents which target cycling cells (9). In endometrial cancer, the cancer stem cell hypothesis has been studied in vitro using the isolation of colony forming units, side population with dye efflux capacity, and tumor spheres $(10,11)$. Besides, the chemoresistance characteristic of stemness of CSCs in endometrial cancer has been shown in CSC phenotype and associated with CSC markers.

Activation of autophagy pro-survival pathways is a mechanism of resistance to several therapies including radiotherapy and chemotherapy using oxazaphosphorine, taxanes, and platinum-derived agents in various human cancers $(12,13)$. Autophagy seems to be related to ALDH1 expression in breast cancer and is fundamental for tumorigenesis in hypoxic environment (14). Autophagy is involved in endometrial tumor growth and cisplatin resistance (15), autophagy inhibition enhances sensitivity of endometrial carcinoma cells to paclitaxel (5). In our previous study, we found miR-218 inhibited HMGB1-mediated autophagy in 
endometrial carcinoma cells during chemotherapy (16). These results suggest that autophagy is closely related to chemosensitivity in endometrial cancer.

It is proposed that there is a close relationship between cancer stem cells and autophagy. Accumulating evidence provides insight into the function of autophagy in maintenance, plasticity and survival (17-19). CSCs have higher autophagy than normal cancer cells and are more sensitive to autophagy inhibition compared to cells not expressing CSC markers (20). It was demonstrated that autophagy is essential for CSC maintenance. Autophagy enriched the population of colorectal and liver CSCs and participated in maintaining the stemness of colorectal and liver CSCs $(21,22)$. Moreover, reduced 'stemness' were observed after CQ-mediated autophagy inhibition in sorted MDA-MB-231 CSCs (19). The increasement of spheres could be reversed by 3-MA treatment (23). Besides, CQ effectively targets CSCs via autophagy inhibition in triple-negative breast cancer (24). These results suggested that autophagy is closely associated with the stemness of CSCs and could be an important mechanism that drives the survival and multidrug resistance of CSCs (25-27). In addition, it was found that autophagy could be a key factor in maintaining the homeostasis of cancer stem cells and normal cancer cells and was able to induce the dynamic transformation between normal tumor cells to CSC of pancreatic cancer (28). However, if CSC autophagy plays a role in the poor chemosensitivity of endometrial cancer is still unknown. We put forward the hypothesis that chemotherapy-induced autophagy activation triggers the dynamic transformation from ordinary tumor cells to cells possessing stemness properties then improve the chemoresistance. Additionally, as the novel mediator of endometrial cancer autophagy, EIG121 could play important role in the stemness of ECSCs.

\section{Materials and methods}

Cell line models and spheriod culture conditions. Human endometrial cancer cell line JEC was purchased from the Cell Bank of Chinese Academy of Sciences (CAS). JEC cells were cultured in DMEM medium with $10 \%$ fetal bovine serum, $100 \mathrm{U} / \mathrm{ml}$ penicillin and $100 \mathrm{U} / \mathrm{ml}$ streptomycin at $37^{\circ} \mathrm{C}$ in a humidified incubator with $5 \% \mathrm{CO}_{2}$.

Conventional 2-D cultures was performed for the selfrenewal and successive spheriod generation experiments according to related references (29-33). Spheroid culture conditions: parental cell lines or the floating spheres were plated in serum-free sphere formation media (SFM): low-glucose (1 g/l) DMEM and supplemented with L-glutamine, sodium pyruvate, penicillin/streptomycin (Wisent Inc.), $20 \mathrm{ng} / \mathrm{ml}$ basic FGF, $20 \mathrm{ng} / \mathrm{ml} \mathrm{EGF}$, and B27 (Invitrogen, Grand Island, NY, USA), $100 \mathrm{mg} / \mathrm{ml}$ gentamycin using 6-well ultra-low attachment plates (Corning Inc., Tewksbury, MA, USA) (31). Spheres were dissociated with trypsin every 7 days and split at 1:3 ratio for the next passage generation. For sphere formation assay, $5 \times 10^{4}$ cells were seeded in ultra-low attachment 6-well plate (Corning Inc.) in $2 \mathrm{ml} \mathrm{SFM/well} \mathrm{for} 2$ weeks. For self-renewal assay, cells were diluted into $\sim 1-3$ cells/well in 96-well ultra-low attachment plates (Corning Inc.) using SFM for 2 weeks, both the media and the drugs were replaced every 3 days. Then the floating spheres were photographed at x100 magnification (Nikon Eclipse TS100). Sphere number was determined by ImageJ program.

Microbead sorting and flow cytometric analysis of $\mathrm{CD} 133^{+} /$ $C D 44^{+}$cells. Microbead sorting was performed using CD133 and CD44 microbead kit (Miltenyi Biotec, Germany). JEC cells were adjusted into $1 \times 10^{8} / \mathrm{ml}$ and centrifuged at $1,300 \mathrm{rpm}$ for $5 \mathrm{~min}$, the supernatant was discarded and cells were resuspened in $300 \mu \mathrm{l}$ cold buffer, then mixed softly. The remaining steps were performed according to the manufacturer's instructions. After CD133 sorting, the appropriate number of $\mathrm{CD}_{133}{ }^{+}$cells were expanded for 7 days by culture and then harvested, sorted with CD44 microbeads for the enrichment

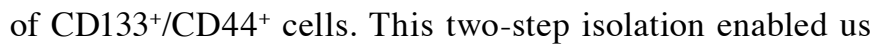
to obtain a suffcient number of $\mathrm{CD} 133^{+} / \mathrm{CD} 44^{+} \mathrm{CSC}$ for the experiment.

To verify the purity of the isolated $\mathrm{CD} 133^{+} / \mathrm{CD} 44^{+} \mathrm{CSCs}$ or spheres of different generations, flow cytometric analysis of $\mathrm{CD}_{133}{ }^{+} / \mathrm{CD} 44^{+}$cells was performed with CD133-FITC and CD44-PE antibodies (Miltenyi Biotec) according to the manufacturer's instructions using a FACSCalibur instrument (Beckman Coulter Life Sciences, USA).

Lentivirus and cell infection. For EIG121 knockdown, lentiviral constructs containing EIG121 shRNA (TRCN0000263309 and TRCN0000263310) were purchased from Sigma. JEC cells stably expressing Lv-con-shRNA or EIG121 shRNA were generated by lentiviral infection at MOI 25 and selected with $2 \mathrm{mg} / \mathrm{ml}$ puromycin.

Quantitative real-time PCR (QPCR). Total RNA was extracted with the TRIzol reagent (Invitrogen, USA) and cDNA was reverse-transcribed using a reverse transcription kit (Fermentans, Germany) according to the manufacturer's protocol. Quantitative detection of RT products was performed using SYBR Green qRCR Mix (Toyobo, Japan). The PCR was performed using Fluorescence quantitative PCR instrument 7300 (ABI PRISM, USA). The PCR reaction condition was as follows: $95^{\circ} \mathrm{C}$ for $3 \mathrm{~min}, 95^{\circ} \mathrm{C}$ for $10 \mathrm{sec}, 58^{\circ} \mathrm{C}$ for $30 \mathrm{sec}$, and $72^{\circ} \mathrm{C}$ for $30 \mathrm{sec}$, 40 cycles, to obtain fluorescence intensity. $\beta$-actin was used as an internal control. The specific primers are listed in Table I. Relative mRNA expression levels were determined by the $2^{-\Delta \Delta \mathrm{Ct}}$ method in comparison with control group.

Western blotting. Cells were lysed in RIPA buffer and cleared by centrifugation at $13,000 \mathrm{rpm}$ for $10 \mathrm{~min}$. The proteins (100 mg) were resolved in a $12 \%$ SDS-PAGE gel and transferred to a nitrocellulose membrane. Primary antibodies against the LC3B antibody ( $2 \mu \mathrm{g} / \mathrm{ml}$, ab81785, Abcam, USA), EIG121 (1:1,000, ab156275, Abcam), Beclin1 (1:1,000, ab14071, Abcam), CD133 (1:500, 18470-1-AP, Proteintech, China), CD44 (1:500, 15675-1-AP, Proteintech), OCT4 (1:1,000, ab181557, Abcam), c-Myc (1:500,10828-1-AP, Proteintech), CK4 (1:500, ab155406, Abcam), and ABCG2 (1:1,000, ab108312, Abcam), or $\beta$-actin (1:2,000, LCA01, Auragene, Changsha, China) were added to the membrane in $8 \%$ non-fat milk and incubated at $4^{\circ} \mathrm{C}$ overnight. After extensive washing, the membrane was incubated in $8 \%$ non-fat milk containing HRP conjugated anti-rabbit secondary antibody (1:2,000, SA009, Auragene) or anti-mouse secondary antibody (1:2,000, SA002, Auragene) 
Table I. Sequences of qRT-PCR primers.

\begin{tabular}{|c|c|c|}
\hline Gene & Primer type & Sequence \\
\hline \multirow[t]{2}{*}{ CD133 } & Sense & TCAAGGACTTGCGAACTCTC \\
\hline & Antisense & GTCTCCTTGATCGCTGTTG \\
\hline \multirow[t]{2}{*}{ CD44 } & Sense & AGCAGCACTTCAGGAGGTTAC \\
\hline & Antisense & CCATGTGAGTGTCTGGTAGCA \\
\hline \multirow[t]{2}{*}{ OTC4 } & Sense & TTCAGCCAAACGACCATCT \\
\hline & Antisense & GCTTTGCATATCTCCTGAAGA \\
\hline \multirow[t]{2}{*}{ c-Mcy } & Sense & CTGAGGAGGAACAAGAAGATGA \\
\hline & Antisense & GCTGCGTAGTTGTGCTGATG \\
\hline \multirow[t]{2}{*}{ CK4 } & Sense & TCCTGAAGGTCCTCTATGATGCG \\
\hline & Antisense & CGCTTGCTGTGGGCATCTTT \\
\hline \multirow[t]{2}{*}{$\mathrm{ABCG} 2$} & Sense & GCCGTGGAACTCTTTGTGGTAG \\
\hline & Antisense & CTGCCTTTGGCTTCAATCCTAAC \\
\hline \multirow[t]{2}{*}{ ALDH1 } & Sense & TTACCTGTCCTACTCACCGATT \\
\hline & Antisense & СААСАТССТССТТАТСТССТТС \\
\hline \multirow[t]{2}{*}{ Beclin 1} & Sense & TGTGGAATGGAATGAAATCAA \\
\hline & Antisense & CCCCCAGAACAGTACAACGGC \\
\hline \multirow[t]{2}{*}{$\operatorname{Atg} 5$} & Sense & TAAGTTTGGCTTTGGTTG \\
\hline & Antisense & TTCCCTTTCAGTTATCTCAT \\
\hline \multirow[t]{2}{*}{$\operatorname{Atg} 7$} & Sense & ATGCCTGGGCATCCAGTGAACTT \\
\hline & Antisense & CATCATTGCAGAAGTAGCAGCCA \\
\hline \multirow[t]{2}{*}{ EIG121 } & Sense & GGGACCAAGAACAACAAGAT \\
\hline & Antisense & TGAGGGTAAAGTGATGGAAGTA \\
\hline \multirow[t]{2}{*}{$\beta$-actin } & Sense & AGGGGCCGGACTCGTCATACT \\
\hline & Antisense & GGCGGCACCACCATGTACCCT \\
\hline
\end{tabular}

for $30 \mathrm{~min}$ at room temperature. The AuraECL detection kit (Auragene) was used to visualize the target bands.

$H \& E$ and immunofluorescence staining. Cells were cultured on cover glasses coated with $0.1 \%$ gelatin in PBS in 6-well tissue culture plates with DMEM. The cells were incubated overnight then washed with PBS, and fixed in $4 \%$ paraformaldehyde for $15 \mathrm{~min}$. They were then permeabilized in $0.2 \%$ Triton X-100 for 10 min prior to blocking in 6\% bovine serum albumin (BSA) for $30 \mathrm{~min}$. For H\&E staining, cells were washed using PBS 3 times then stained with hematoxylin for $10 \mathrm{~min}$. After washing, stained with eosin for $15 \mathrm{~min}$, dehydrated by anhydrous alcohol for $10 \mathrm{sec}$ and dried. Subsequently, stained cells were photographed at x400 magnifcation (Nikon Eclipse TS100). For immunofluorescence staining, the cells were incubated overnight with anti-LC3B $(1: 200,12741 \mathrm{~S}$, Cell Signaling, USA) at $4{ }^{\circ} \mathrm{C}$, followed by incubation with goat anti-rabbit IgG (H+L)-Cy3 (1:200, SA012, Auragene) for $1 \mathrm{~h}$ at room temperature in dark. Nuclei were counterstained with DAPI (10 $\mu \mathrm{g} / \mathrm{ml}, \mathrm{C} 0065$, Solarbio, China). Finally, cells were analyzed using a confocal fluorescence microscope (BX50; Olympus, Japan) and the percentage of cells with LC3 puncta was calculated with the help of Image-Pro Plus 6.0.
Cell viability assay. ECSCs were dispersed and seeded into 96-well plates at $5 \times 10^{3}$ cells/well and incubated with DMEM containing PTX $(20 \mu \mathrm{g} / \mathrm{ml})$ alone or with CQ $(10 \mu \mathrm{M}) / 3-\mathrm{MA}$ $(1 \mathrm{mM})$ respectively for $24 \mathrm{~h}$. MTT solution $(10 \mu \mathrm{l})$ was added to each well and incubated at $37^{\circ} \mathrm{C}$ for $4 \mathrm{~h}$, then $150 \mu \mathrm{DMSO}$ was added to each well. Ten minutes later, the absorbance at $570 \mathrm{~nm}$ was monitored using a microplate reader (BioTek) to assess cell viability. Cell growth inhibition was normalized and expressed relative to the absorbance of cells treated with DMSO alone.

Phenotypic recovery assay. It was known that when the culture environment is restored to normal culture condition of tumor cells, the spheres would differentiate to normal adherent tumor cells and proliferation. So, to some extent, the extension of cells in 6-well plates reflect the cell viability. The phenotypic recovery assay was performed to determine the re-differentiation ability of different cells. P3 JEC spheres or $\mathrm{CD} 33^{+} / \mathrm{CD}_{4} 4^{+} \mathrm{CSC}$ s were digested with $0.05 \%$ trypsinase to obtain single cell suspension, then the cells were inoculated in 6-well normal cell culture plate filled with complete DMEM medium containing CQ or 3-MA, respectively. When the cell was completely adherent, the phenotypic change was observed and photographed at x100 magnification (Nikon Eclipse TS100). The cell-free areas were filled with black using Photoshop and measured by Image-Pro Plus 6.0.

Tumorigenicity assay and IHC staining. Animal experiments were performed in accordance with the Guide for the Care and Use of Laboratory Animals of The Affiliated Tumour Hospital of Xiangya Medical School of Central South University. The protocol was approved by the Committee on the Ethics of Animal Experiments of The Affiliated Tumour Hospital. NOD/SCID mice at age of 3-5 weeks, male, were maintained in pathogen-free conditions at animal facility. The JEC, Lv-Con, and Lv-EIG121-shRNA cells were resuspended in serum-free medium and mixed with Matrigel at the ratio of 1:1. NOD/SCID mice were randomly divided into 3 groups $\left(n=4\right.$ per group). Cells $\left(1 \times 10^{6}\right)$ were inoculated subcutaneously into the inguinal folds of NOD/SCID mice. Tumor formation was evaluated regularly after injection by palpation of injection sites. At the end of experiment, the mice were sacrificed under deep anesthesia with pentobarbital. The tumors were then dissected and captured. The primary tumors were immunostained for PCNA and active caspase-3 as previously described (34).

Statistical analysis. The data are presented as mean \pm standard deviation. The means of groups were compared with one-way analysis of variance, and after checking for equal variance, comparisons between two means were performed using the least significant difference (LSD) method. Student's t-test was used for two group's comparison. Analysis of variance was used for statistical analyses. $\mathrm{P}<0.05$ was considered as statistically significant.

\section{Results}

$\mathrm{CD} 133^{+} / \mathrm{CD} 44^{+}$cells exhibit higher level of autophagy. It has been reported that $\mathrm{CD}_{133^{+}}$cells exhibit properties of CSCs 
A
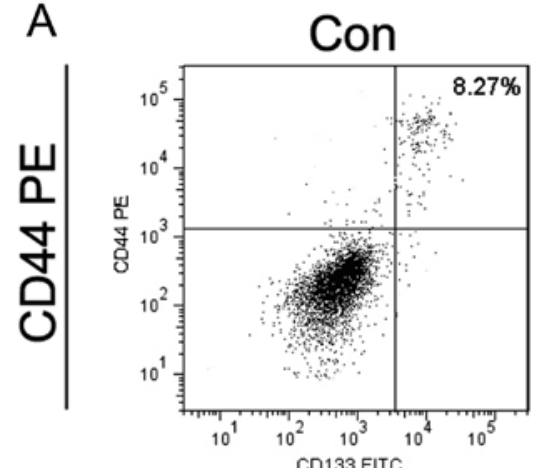

\section{$\mathrm{CD} 133^{+} / \mathrm{CD} 44^{+}$}

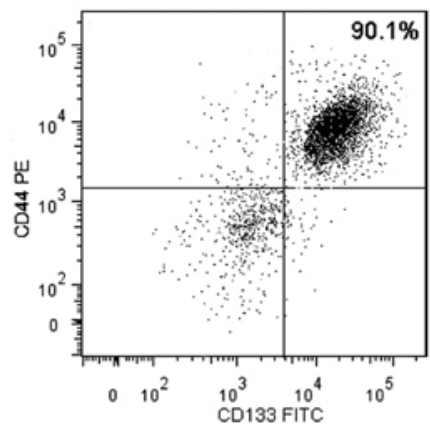

B

CD133 FITC
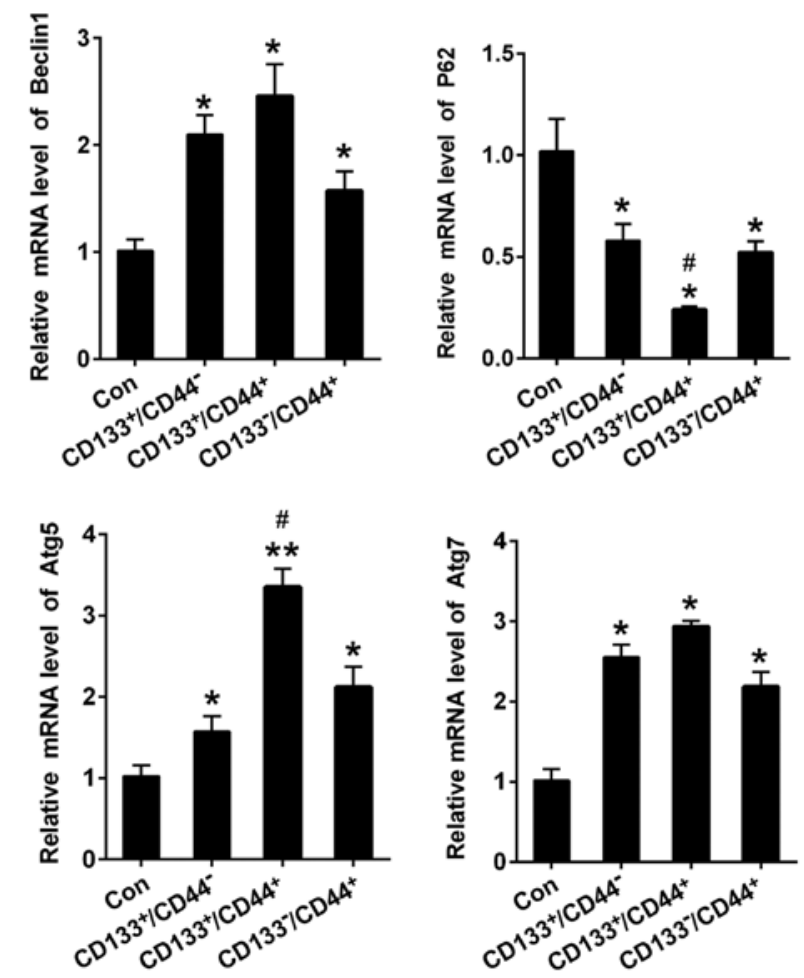

Figure $1 . \mathrm{CD} 133^{+} / \mathrm{CD} 44^{+}$cells exhibit higher level of autophagy. (A) Flow cytometry analysis was performed to detect the ratio of $\mathrm{CD} 133^{+} / \mathrm{CD} 44^{+}$cells before and after sorting from JEC cells, the result of original JEC cells (Con) without sorting is shown on the left and the result of CD133 $/ \mathrm{CD} 44^{+}$cells is shown on the right. (B) The relative mRNAs levels of classic autophagy markers as indicated were determined by QPCR, original JEC cells without sorting used as control (Con). ${ }^{*} \mathrm{P}<0.05 ;{ }^{* *} \mathrm{P}<0.01$ vs. control, ${ }^{*} \mathrm{P}<0.05$ vs. $\mathrm{CD} 133^{+} / \mathrm{CD} 44$.

and CD44 is another important marker of ECSCs (35-37). To better understand the underlying mechanism responsible for low chemosensitivity in $\mathrm{EC}, \mathrm{CD} 133^{+} / \mathrm{CD} 44^{+}$cells were sorted from the JEC cell lines by CD133 and CD44 microBeads (38). The purity of $\mathrm{CD} 33^{+} / \mathrm{CD} 44^{+}$cells before and after sorting from JEC was 8.27 and $90.1 \%$, respectively (Fig. 1A). The QPCR was performed to detect the autophagy markers in JEC control, CD $133^{+} / \mathrm{CD}_{4} 4^{-}, \mathrm{CD} 133^{+} / \mathrm{CD} 44^{+}$and $\mathrm{CD} 133 \% \mathrm{CD}^{\circ} 4^{+}$ cells. The results showed that Beclin1, Atg5, Atg7 mRNA levels were significantly enhanced but the P62 was obviously reduced in $\mathrm{CD} 133^{+} / \mathrm{CD} 44^{+}$cells compared to $\mathrm{JEC}$ cells (Fig. 1B). Besides, the mRNA alteration of Atg5 and P62 exhibited significance between $\mathrm{CD} 133^{+} / \mathrm{CD} 44^{-}$and $\mathrm{CD} 133^{+} /$ $\mathrm{CD} 44^{+}$groups. The results demonstrated that the $\mathrm{CD} 133^{+} /$ $\mathrm{CD} 44^{+}$cells which exhibit CSC properties possess higher autophagy.
Stemness kept in line with autophagy in successive spheroid JEC generations. Firstly, it was found that bead sorted cells $\left(\mathrm{CD} 133^{+} / \mathrm{CD} 44^{+}\right.$cells) are enriched for autophagosomic LC3B II over parental cells (Con) alone which suggeted the autophagy level of ECSCs would be higher than normal cancer cells (Fig. 2A).

Spheroid culture is a mainstream method to obtain cells exhibiting properties of CSCs. In order to observe the autophagy dynamic changes in the process of stemness dynamic changing, successive spheroid cultures were performed from passage 1 (P1) to passage 4 (P4). QPCR was performed to detect the relative mRNA level of CSC markers and autophagy markers. The results showed that the relative expression of CSC marker CD133, CD44, Oct4, c-Myc and drug resistance marker ABCG2 were increased but the differentiation marker CK4 decreased obviously from P0 (Con) to P3. Besides, the 

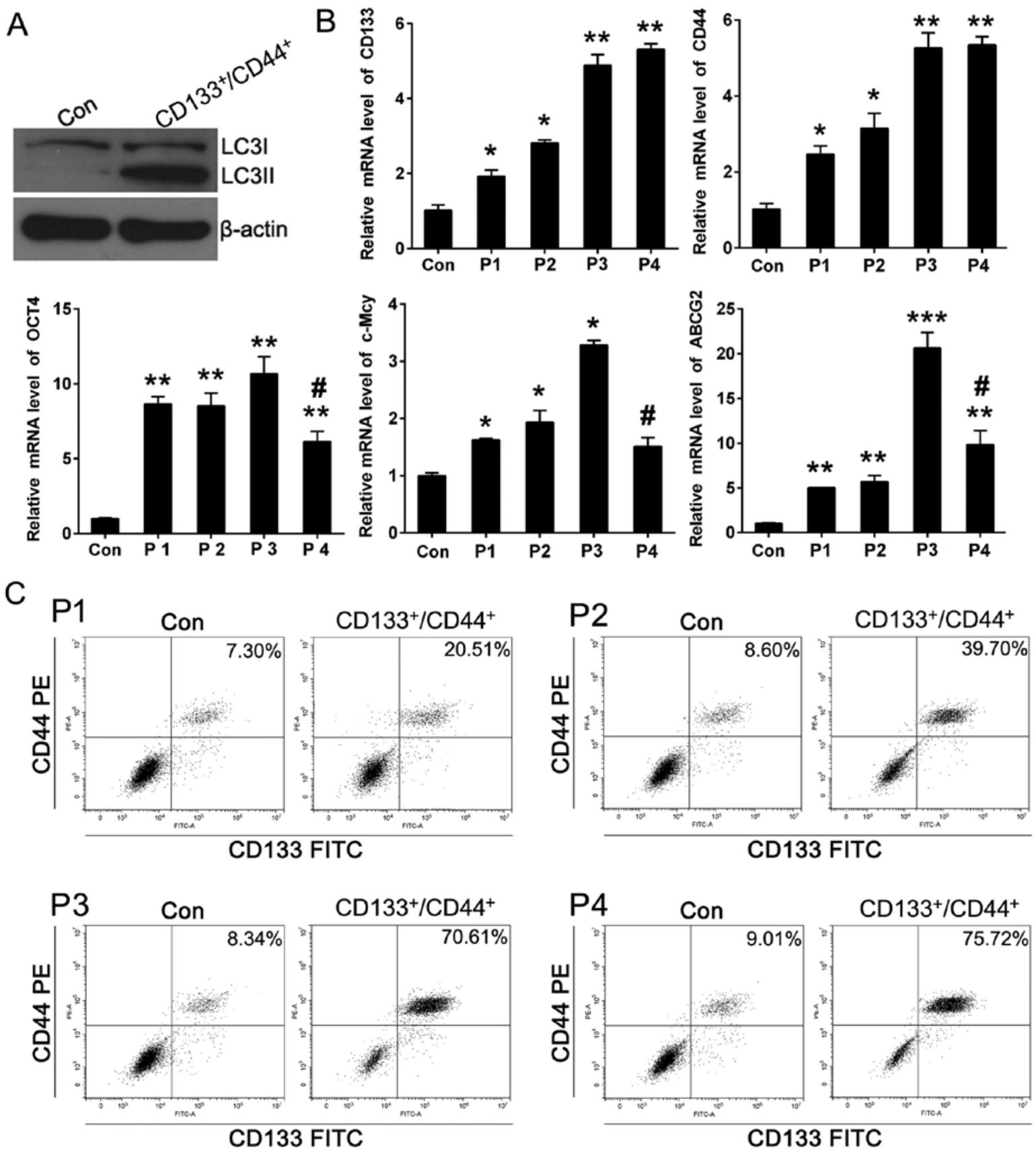

D

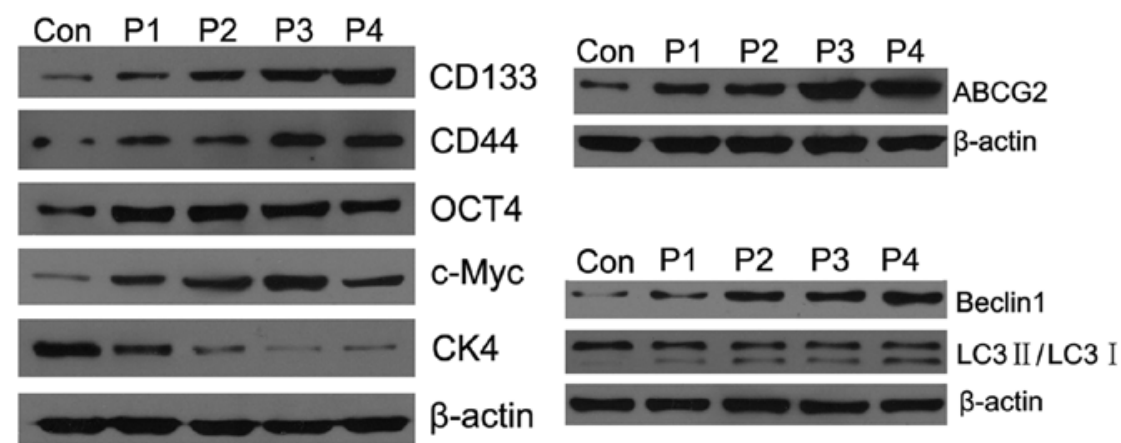

Figure 2. Stemness kept in line with autophagy in successive spheroid cultures of JEC spheres. Western blotting was performed to detect the LC3II/I expression in $\mathrm{CD}_{133} / \mathrm{CD} 44^{+}$cells (A). The relative mRNAs levels and protein expressions of stemness markers as indicated were determined by QPCR in successive spheroid generations (B), parental JEC cells were used as control group (Con), multiple successive spheroid culture was performed from passage 1 (P1) to passage 4 ( $\mathrm{P} 4)$ to obtain the spheres of different passages. ${ }^{*} \mathrm{P}<0.05$ vs. control; ${ }^{* *} \mathrm{P}<0.01$ vs. control; ${ }^{* * *} \mathrm{P}<0.001$ vs. control; ${ }^{\#} \mathrm{P}<0.05$ vs. $\mathrm{P} 3$. Flow cytometry

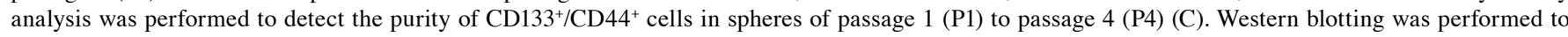
clarify the expression alterations of CSC markers and autophgy markers in spheres of passage 1 (P1) to passage 4 (P4), and the parental JEC cells were used as control (Con) (D). 
mRNA level of ABCG2, c-Myc and CK4 were decreased from the relative peak value when the spheroid generations have undergone $\mathrm{P} 4$ culture but the CD133 and CD44 are still maintained at peak level. On the other hand, flow cytometric staining was used to detect the purity of $\mathrm{CD} 133^{+} / \mathrm{CD} 44^{+}$cells in spheres at different passages, the percentage of $\mathrm{CD}_{133^{+}} /$ CD44 ${ }^{+}$cells increased significantly from $\mathrm{P} 1$ to $\mathrm{P} 3$, but to the $\mathrm{P} 4$ generation, the increasement was not obvious compared to P3 (Fig. 2B and C). We thought the JEC P3 spheres could be partially considered as ECSCs with strongest stemness using the successive spheroid culture method. It was of great interest that the expression of classic autophagy marker Beclin1 and LC3П/I kept in line with the stemness changing, in other words, autophagy was enhanced gradually from P0 to P4 (Fig. 2D). These results allowed to conclude that stemness kept in line with autophagy in successive culture of JEC spheres and the synchronized level suggested the inherent link between ECSCs and JEC autophagy.

Autophagy inhibition decreases the properties of CSCs in JEC spheres. It has been reported that autophagy plays an important role in CSC maintenance, plasticity and survival (17-19) and takes part in the dynamic transformation between normal cancer cells and CSC in pancreatic cancer $(27,28)$. In order to clarify if autophagy inhibition could influence the dynamic transformation of ECSCs, conventional autophagy inhibitors 3-MA and CQ were added during the successive spheroid culture, respectivly, then the relative expression of CSC markers was detected by QPCR and western blotting. Results showed when 3-MA or CQ was added, the CSC markers (CD133, CD44, OCT4 and ABCG2 decreased compared to the control group of the same sphere passage (Fig. 3A and B). To further confirm the effect of autophagy inhibitors, western blotting was performed to detect expression of P62 and LC3II/I in $\mathrm{P} 3$ and $\mathrm{P} 4$ spheres. The experimental results showed that autophagy inhibitor 3-MA addition could increase P62 while decrease the ratio of LC3II/I and CQ addition could increase both P62 and the ratio of LC3II/I compared to spheres without autophagy inhibitor in P3 and P4 JEC spheres (Fig. 3C). Re-differentiation ability is one of the important characteristics of CSCs. For the sake of detecting the re-differentiation ability of JEC spheres, P3 spheres were used to perform phenotypic recovery assay which aims to show whether the addition of autophagy inhibitor could decrease the re-differentiation of JEC spheres. The extension of cells in 6-well plates reflect the cell viability. It was observed that when the $\mathrm{P} 3$ spheres were treated with 3-MA or CQ, the recovery was more difficult to adherent phenotype and proliferation under routine culture conditions (Fig. 3D and E).

Autophagy inhibition enhances sensitivity of ECSCs to paclitaxel. We obtained $\mathrm{CD} 133^{+} / \mathrm{CD} 44^{+}$cells by microBead sorting and CSC markers were detected by QPCR and western blotting. The relative expression of CD133, CD44, ABCG2, OCT4 and ALDH was significantly enhanced in $\mathrm{CD} 133^{+} / \mathrm{CD} 44^{+}$ cells, so that $\mathrm{CD} 133^{+} / \mathrm{CD} 44^{+}$cells would be considered as endometrial carcinoma stem cells (ECSCs) to some extent. Besides, the expression levels of EC autophagy marker EIG121, Beclin1, Atg5, Atg7 and LC3П/I were obviously increased dependent on VS JEC cells (Con). The above demonstrated that the ECSC cells exhibited higher level of autophagy (Fig. 4A). For evaluating the role of autophagy in the PTX chemoresistance of ECSCs, cell viability, self-renewal and phenotypic recovery assays were performed using PTX treatment with or without autophagy inhibitors. The results showed when the ECSCs were treated in combination with 3-MA or CQ, the cell viability attenuated significantly (Fig. 4C). Self-renewal capacity reduced both in sphere size and number (Fig. 4B and D). Phenotypic recovery assays were performed to imitate recurrence after chemotherapy in vitro aiming to show that the addition of autophagy inhibitor could enhance the growth inhibition of PTX of JEC cells, and the extension of cells in 6-well plates reflect the cell viability (Fig. 4E and F) compared to ECSCs treated with PTX only, autophagy inhibition attenuated the cell growth capacity to some extent after removal of drugs and return to normal condition (Fig. 4E and F). Thus, the lower self-renewal capacity was not only embodied in propagating clone numbers but also the offspring sphere size.

EIG121 plays an autophagy-induced role in JEC-obtained ECSCS. It was reported previously that the novel estrogeninduced gene EIG121 regulates autophagy and promotes cell survival under EC stress (39). In this experiment, it was found that EIG121 was increased in ECSCs similarly to other autophagy-associated proteins (Fig. 4A). EIG121 loss-offunction stem cell model was constructed to explore whether the EIG121 could mediate the autophagy in JEC ECSCs. Lv-EIG121-shRNA lentivirus infection of ECSCs was performed. When the relative expression of EIG121 was effectively knocked down by Lv-EIG121-shRNA in ECSCs, the expression of Beclin1, ATG5 and Atg7 were also downregulated in ECSCs (Fig. 5A and B). Overexpression EIG121 would greatly increase cytoplasmic vacuole accumulation in MDA-MB- 213 (39). As cytoplasmic vacuolation is a hallmark of autophagy, the $\mathrm{H} \& \mathrm{E}$ staining was performed on JEC ECSCs at $12 \mathrm{~h}$ after lentivirus infection and it was shown that the JEC-obtained ECSCs contained numerous cytoplasmic vacuoles. However, when the EIG121 was knocked down, cytoplasmic vacuoles became blurred (Fig. 5C). On the other hand, autophagy induction is associated with LC3, conjugated LC3 moves into autophagosomes and tightly binds to the autophagosome membrane. Thus, LC3 translocation is a reliable biomarker of autophagy $(1,40)$. Immunofluorescence staining was performed to detect the LC3 translocation. The results showed that in ECSCs, LC3 expression occurred predominantly in punctuate dot-like structures, consistent with autophagy induction. Whereas in Lv-EIG121-shRNA infected ECSCs, LC3 puncta decreased obviously and LC3 was uniformly distributed in the cytoplasm, the percentage of cells with LC3 puncta was calculated with the help of Image-Pro Plus 6.0 (Fig. 5D and E). These results demonstrated that EIG121 played an autophagy-induced role not only in EC normal cells, but also in JEC-obtained ECSCs.

EIG121 knockdown in JEC cells results in attenuated stemness and tumorigenesis. We considered that autophagy could play an important role in the transformation between JEC cells and JEC-obtained cancer stem cells. Besides, EC novel autophagy-induction protein EIG121 was found to exert autophagy-induction function in ECSCs. Based on this 

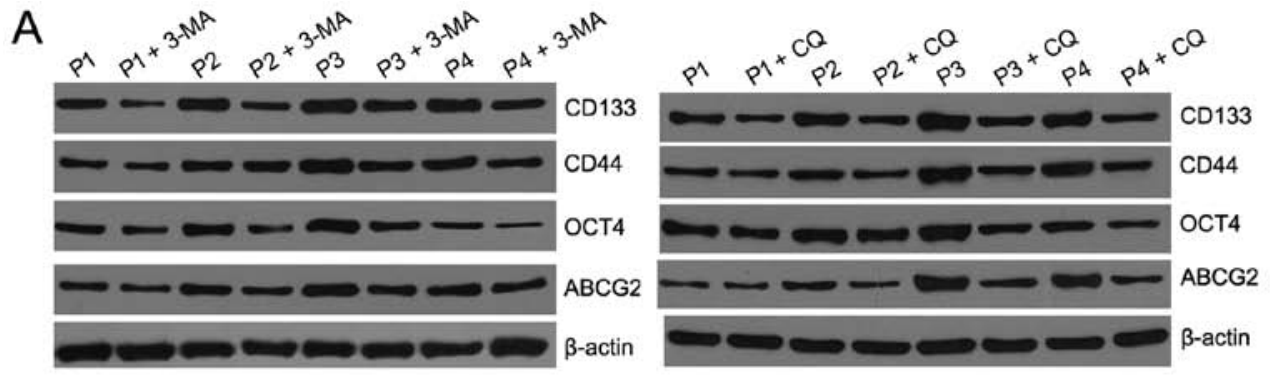

B
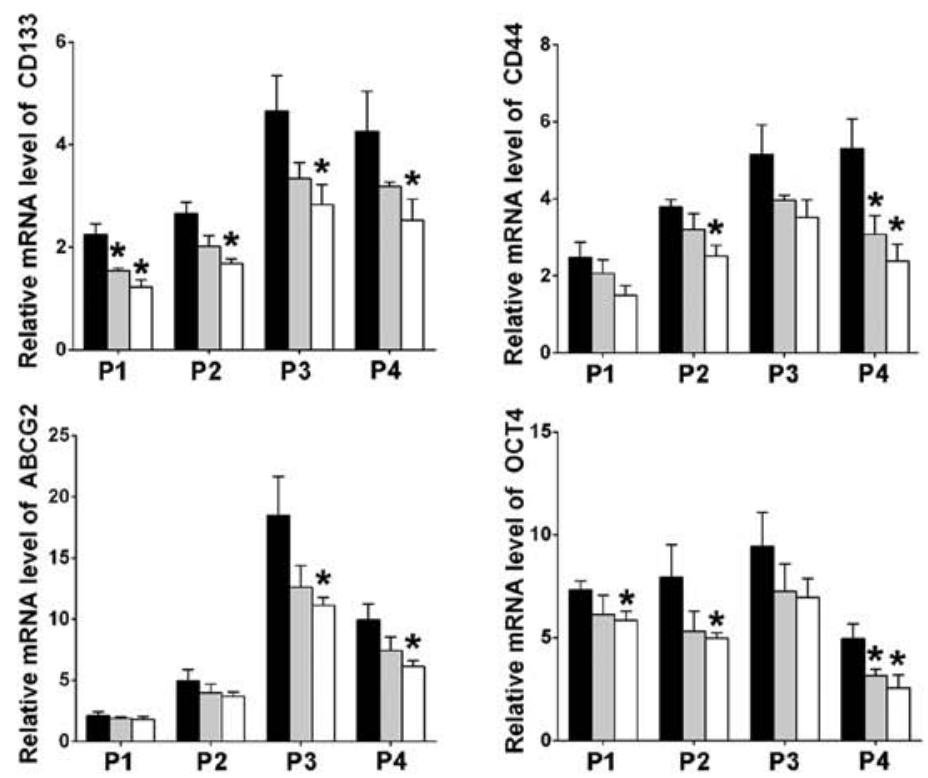

C
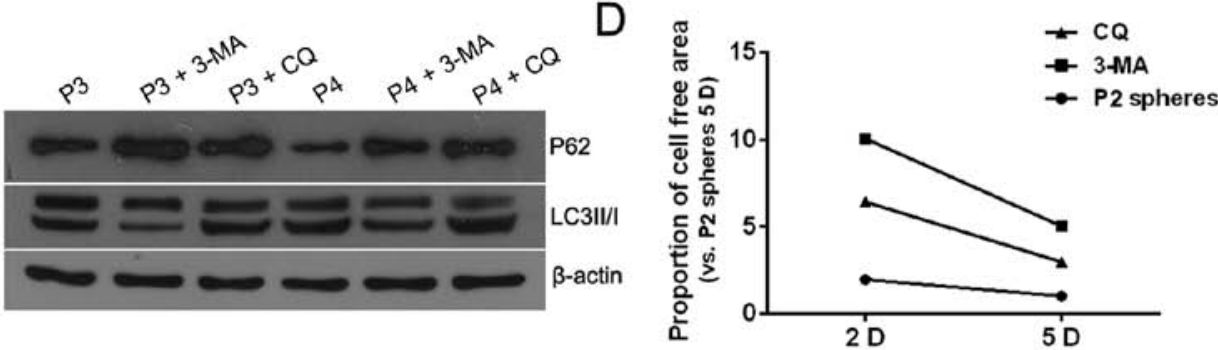

E

P3 spheres

3-MA
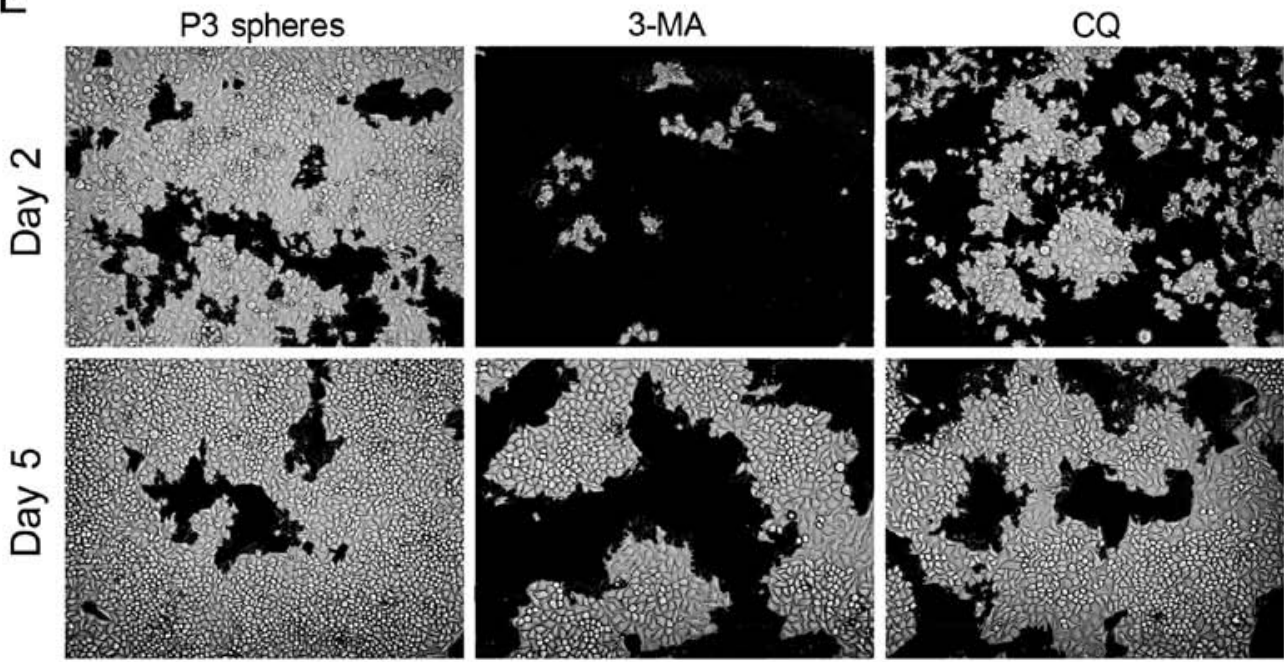

Figure 3. Autophagy inhibition decreases the properties of CSCs in JEC shperes. Autophagy inhibitors 3-MA or CQ were added during multiple successive spheroid culture. The relative mRNA levels and protein expression of stemness markers as indicated were determined by QPCR (A) and western blotting (B). Multiple successive spheroid culture was performed from passage 1 (P1) to passage 4 (P4), spheres of the same passage cultured in the absence of autophagy inhibition were used as control (Con). The protein expression of autophagy-related marker P62 and LC3II/I was determined by western blotting in P3 and P4 spheres with or without autophagy inhibitors (C). Re-differentiation ability of P3 JEC spheres in normal culture conditions was observed on day 2 and day 5 , the cell-free areas were filled with black using Photoshop and measured by Image-Pro Plus 6.0., the proportion of cell-free area is presented vs. P3 spheres $5 \mathrm{D}$ group (D), the images were captured at $\mathrm{x} 100$ magnification (E). ${ }^{*} \mathrm{P}<0.05$ vs. control of the same passage. 


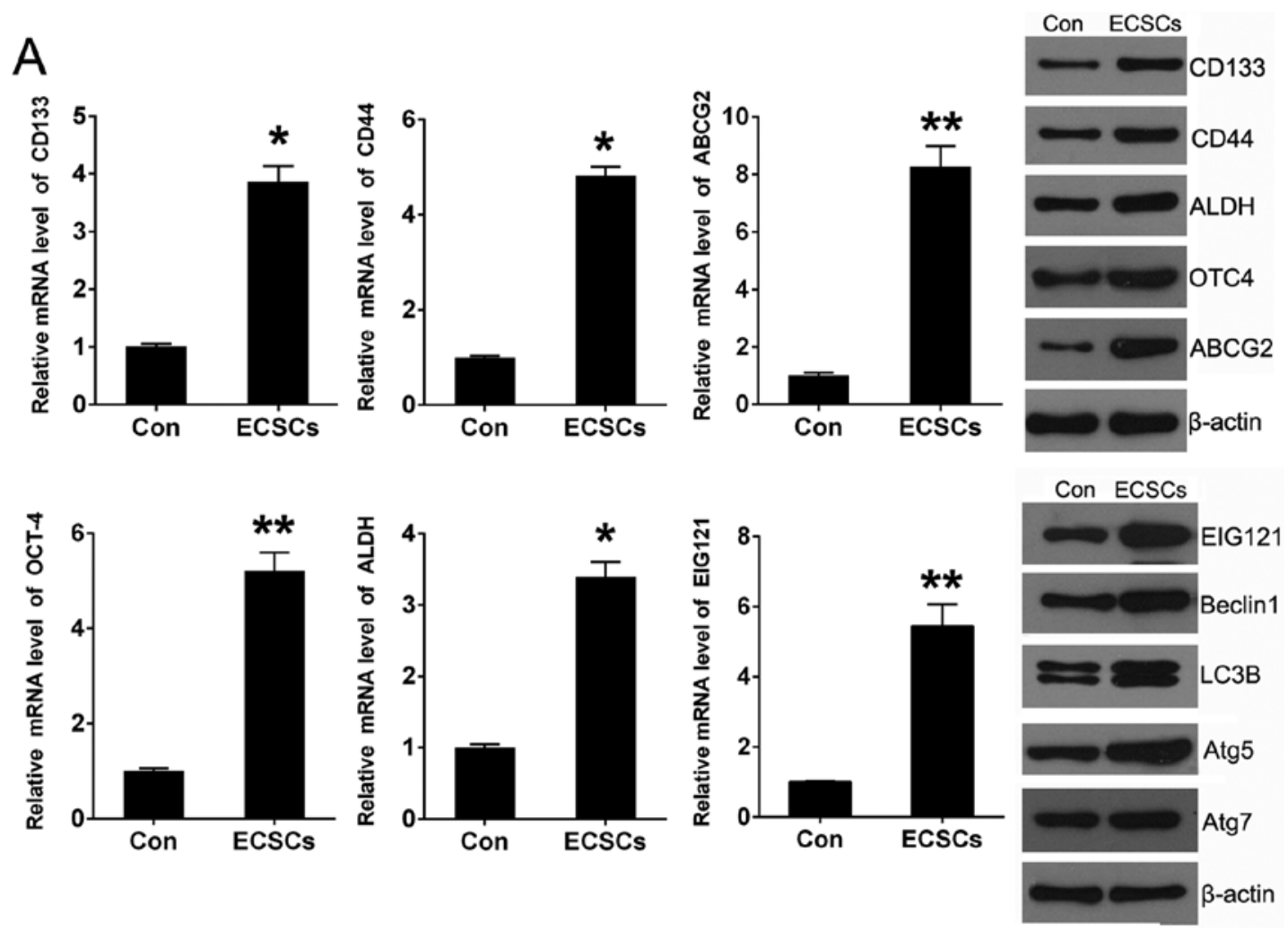

B
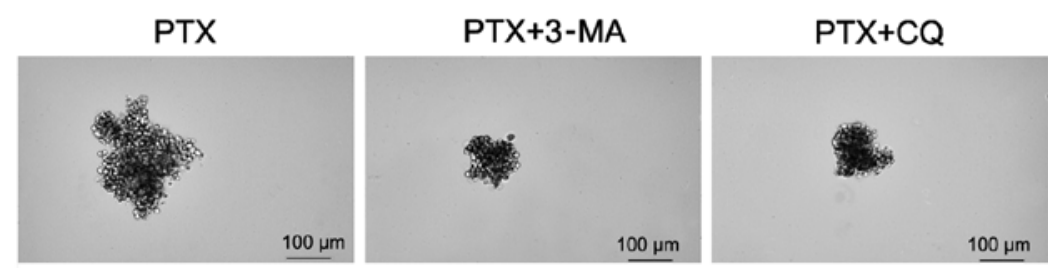

C
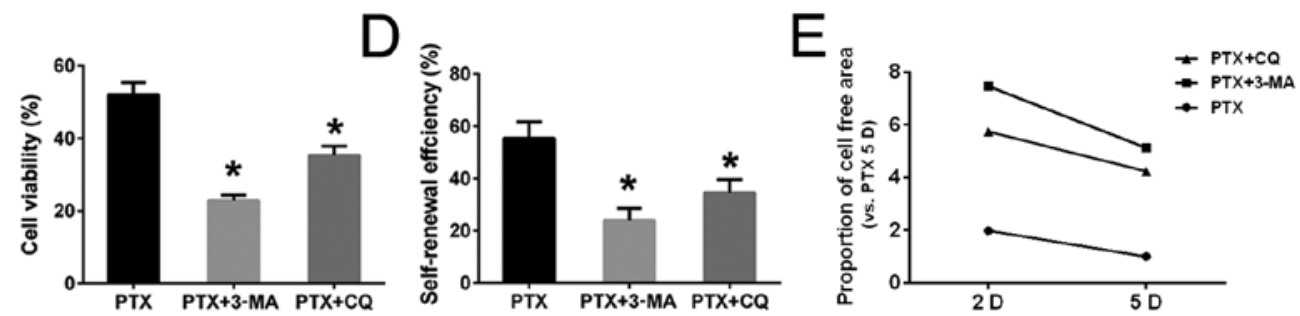

$\mathrm{F}$
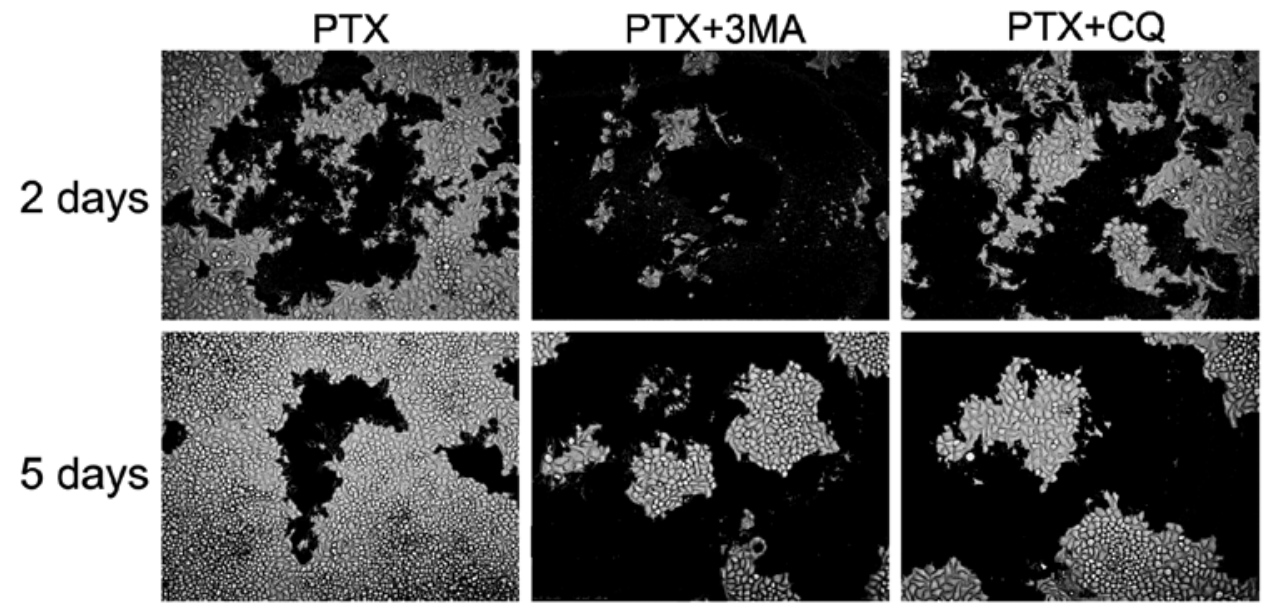

Figure 4. Autophagy inhibition enhances sensitivity of $\mathrm{CD} 133^{+} / \mathrm{CD} 44^{+} \mathrm{ECSC}$ s to paclitaxel. Cancer stem cells were isolated from JEC cells using $\mathrm{CD} 133^{+} / \mathrm{CD} 44^{+}$ microbead sorting. The relative mRNA levels and protein expressions of indicated markers were determined by QPCR and western blotting respectively (A). Parental JEC cells were used as control group (Con). ${ }^{*} \mathrm{P}<0.05$ vs. control; ${ }^{* *} \mathrm{P}<0.01$ vs. control. Self-renewal efficiency of both sphere size (x100 magnification) (B) and sphere number (D), cell viability (C), phenotypic recovery assays (E and F) were performed to detect if autophagy was one of the molecular mechanisms of PTX low response to PTX of JEC ECSCs. "P<0.05 vs. PTX single treated group. The cell-free areas were filled with black using Photoshop and measured by Image-Pro Plus 6.0., the proportion of cell-free area is presented v.s. PTX 5D group (E). 

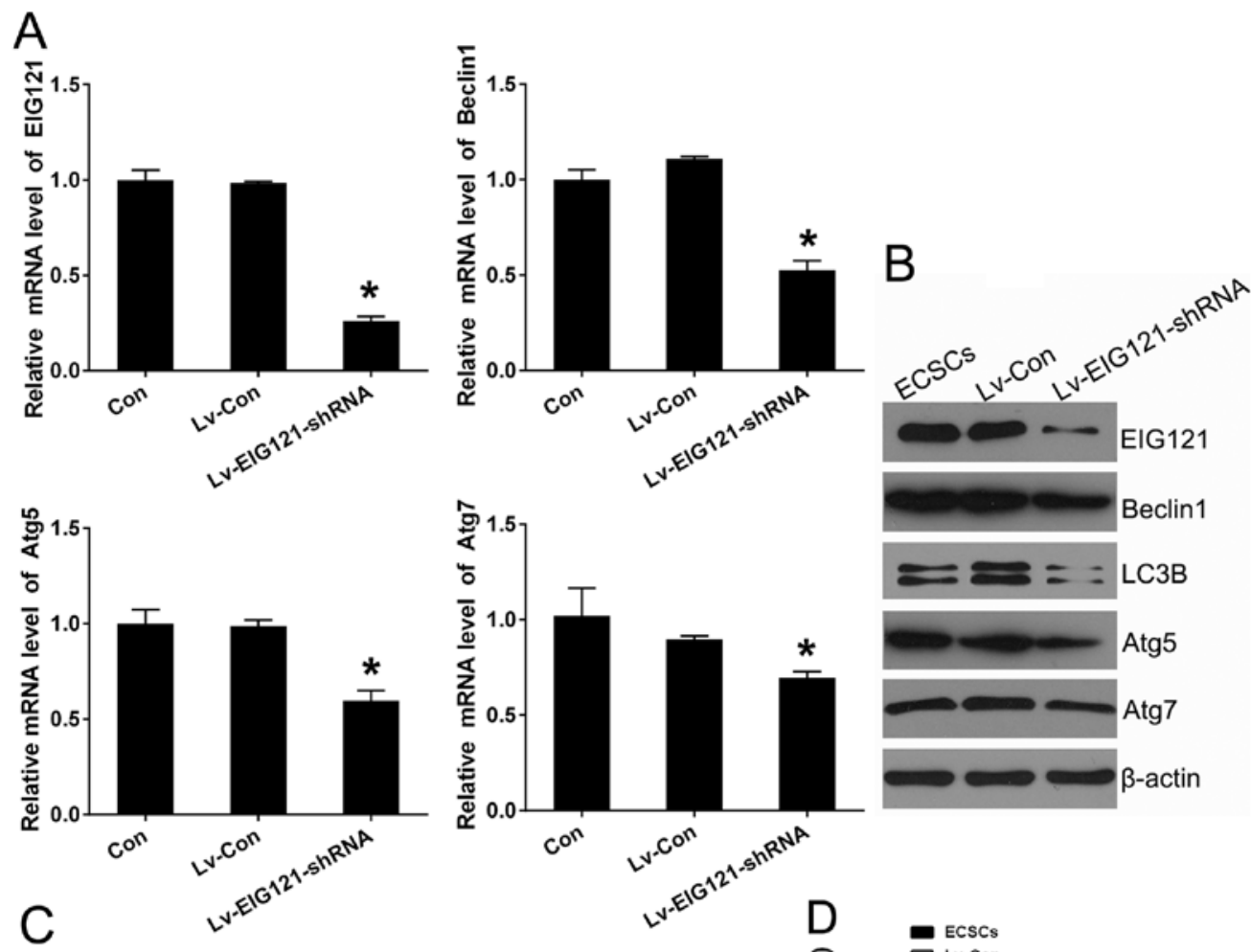

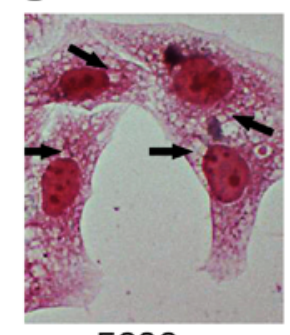

ECSCs

E

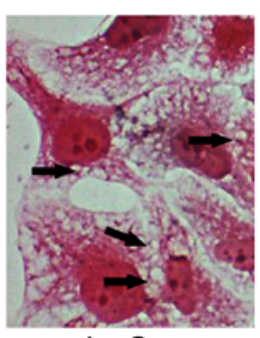

Lv-Con
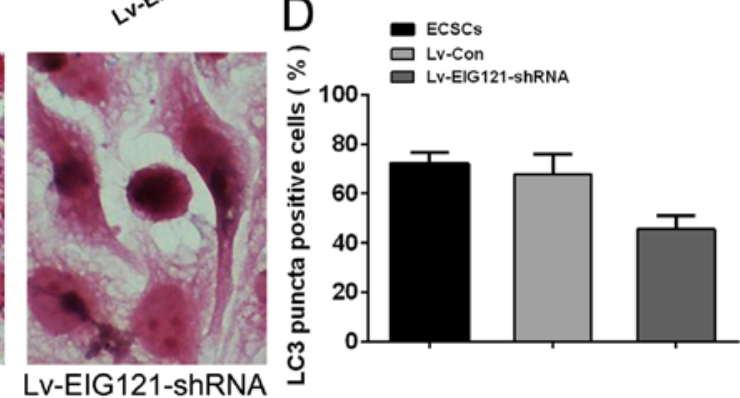

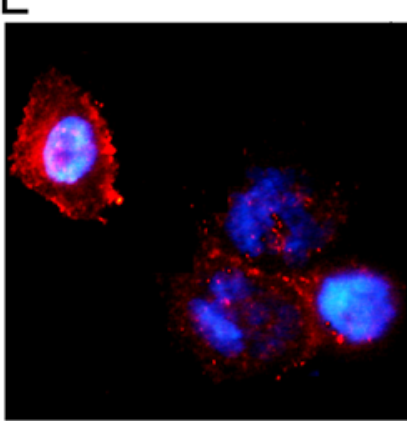

ECSCs

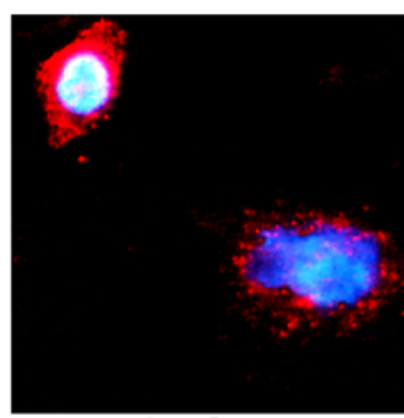

Lv-Con

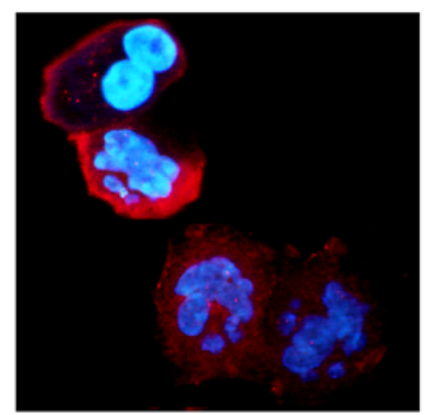

Lv-EIG121-shRNA

Figure 5. EIG121 plays an autophagy-induced role in JEC-obtained ECSCs. The relative mRNA levels and protein expression of EIG121 and autophagy markers as indicated were determined by QPCR (A) and western blotting (B) respectively. JEC CSCs were used as control group (Con). * $<0.05$ vs. control; ECSCs were infected with Lv-EIG121-shRNA or Lv-con lentivirus for $12 \mathrm{~h}$ then fixed and stained with H\&E, cytoplasmic vacuolation (indicated by black arrows) was used as a hallmark of autophagy level (C). Immunofluorescence staining was performed to detect the LC3 puncta and translocation (D and E). The images were captured at x400 magnification.

information, it was hypothesized that the novel autophagyinducing gene EIG121 would mediate the stemness of JEC cells. To explore whether EIG121 expression could affect stemness and tumorigenesis, EIG121 loss-of-function cell model was constructed in JEC cells. Lentivirus (Lv-EIG121shRNA) infected JEC cells exhibited lower relative expression of stemness marker genes of CD133, CD44, ABCG2, OCT4 and ALDH at both mRNA and protein levels (Fig. 6A and B). Besides, Lv-EIG121-shRNA infected JEC cells showed reduced self-renewal capacity in both colony size and number (Fig. 6C and D). Moreover, cells were inoculated into nude mice and all mice developed xenograft tumors at the injection site 20 days after injection. It was found that the tumors formed of the Lv-EIG121-shRNA group were generally smaller than JEC and Lv-Con group (Fig. 6E). Additionally, the average tumor weight was obviously lower in the Lv-EIG121-shRNA group compared to other groups (Fig. 6H). The tumors developed from Lv-EIG121-shRNA cells displayed weaker PCNA 

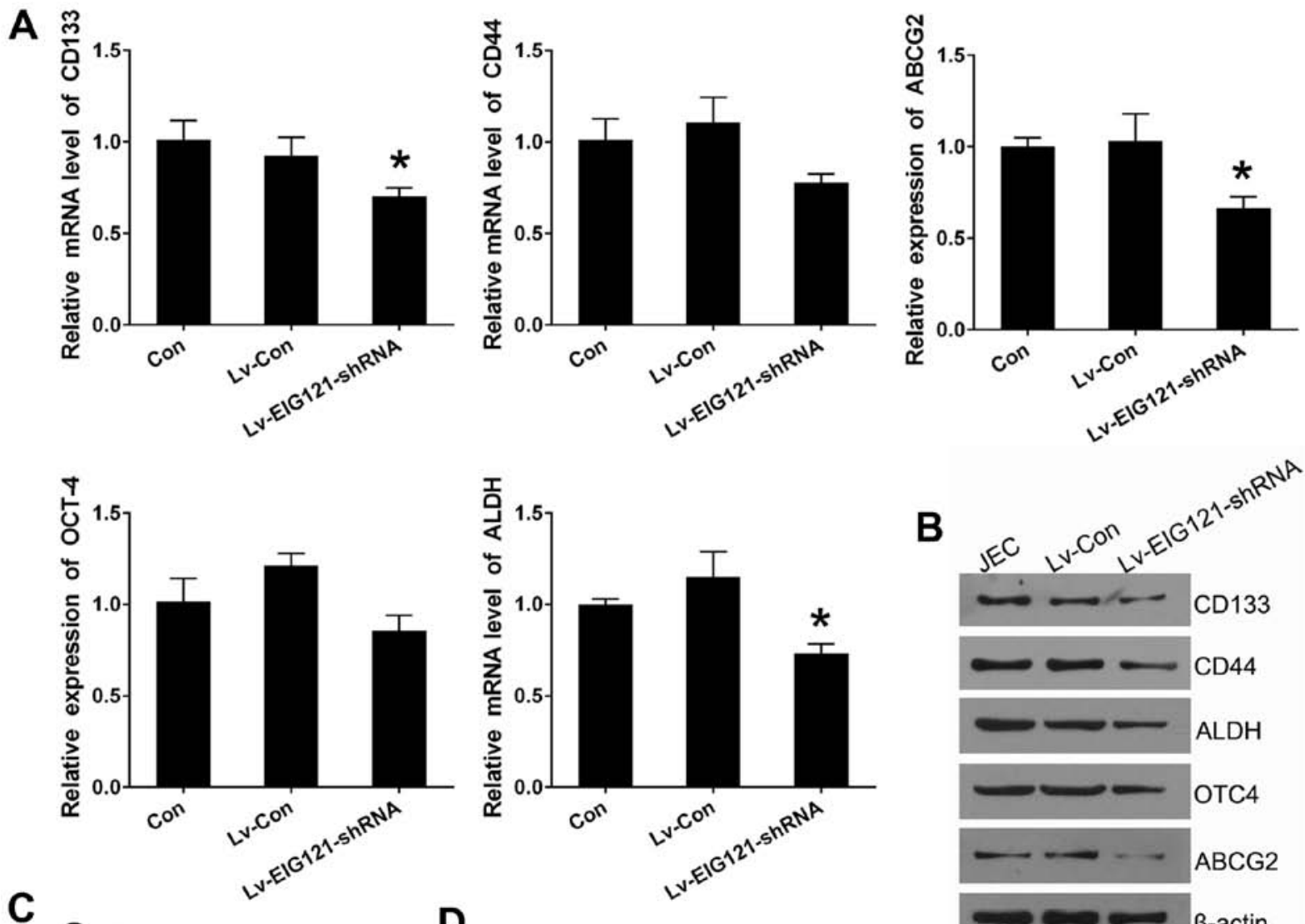

B
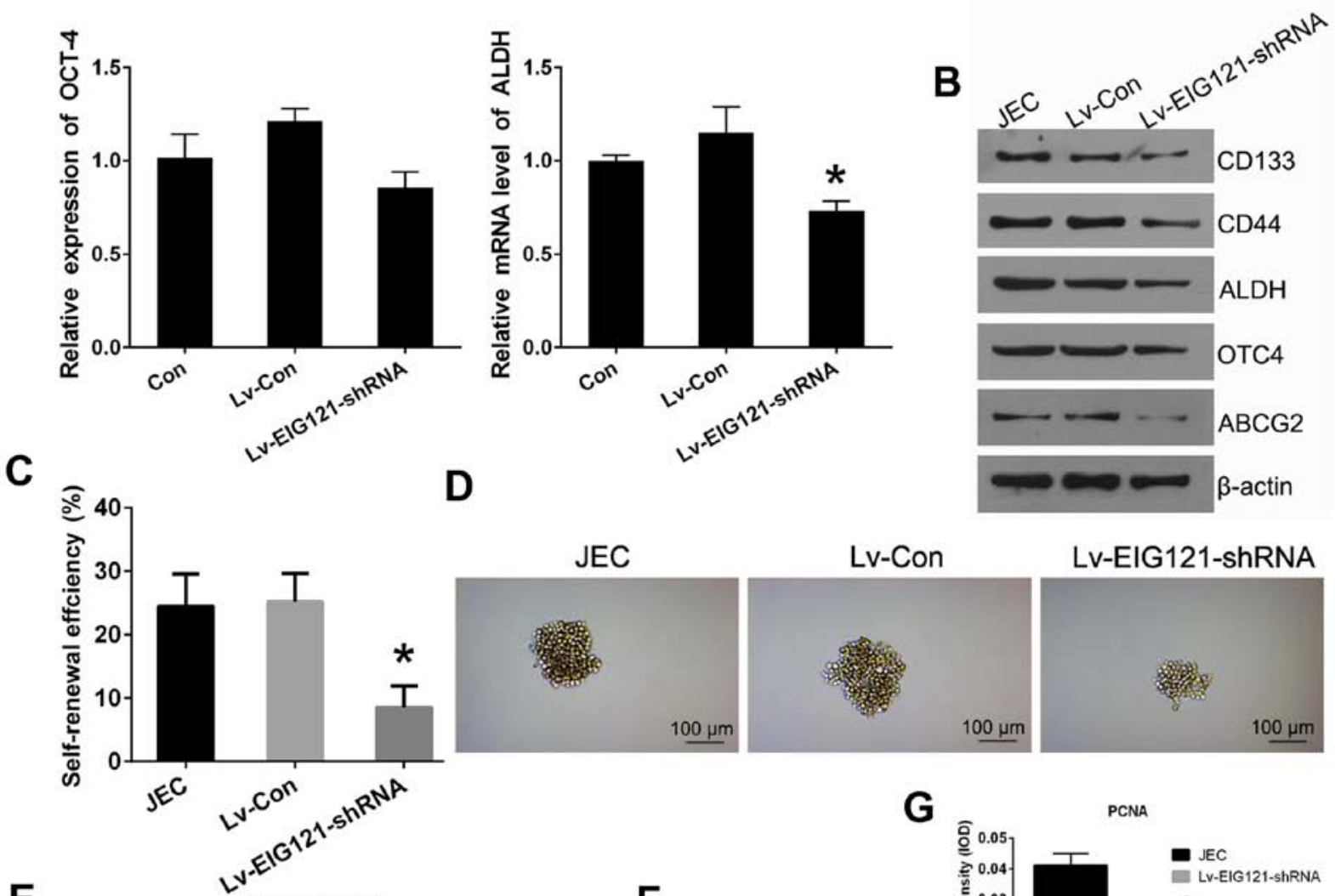

D
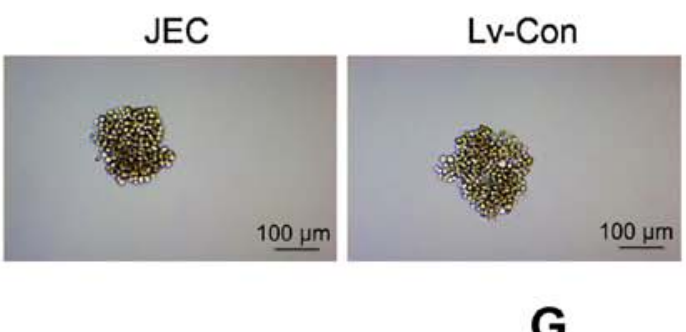

Lv-EIG121-shRNA

E
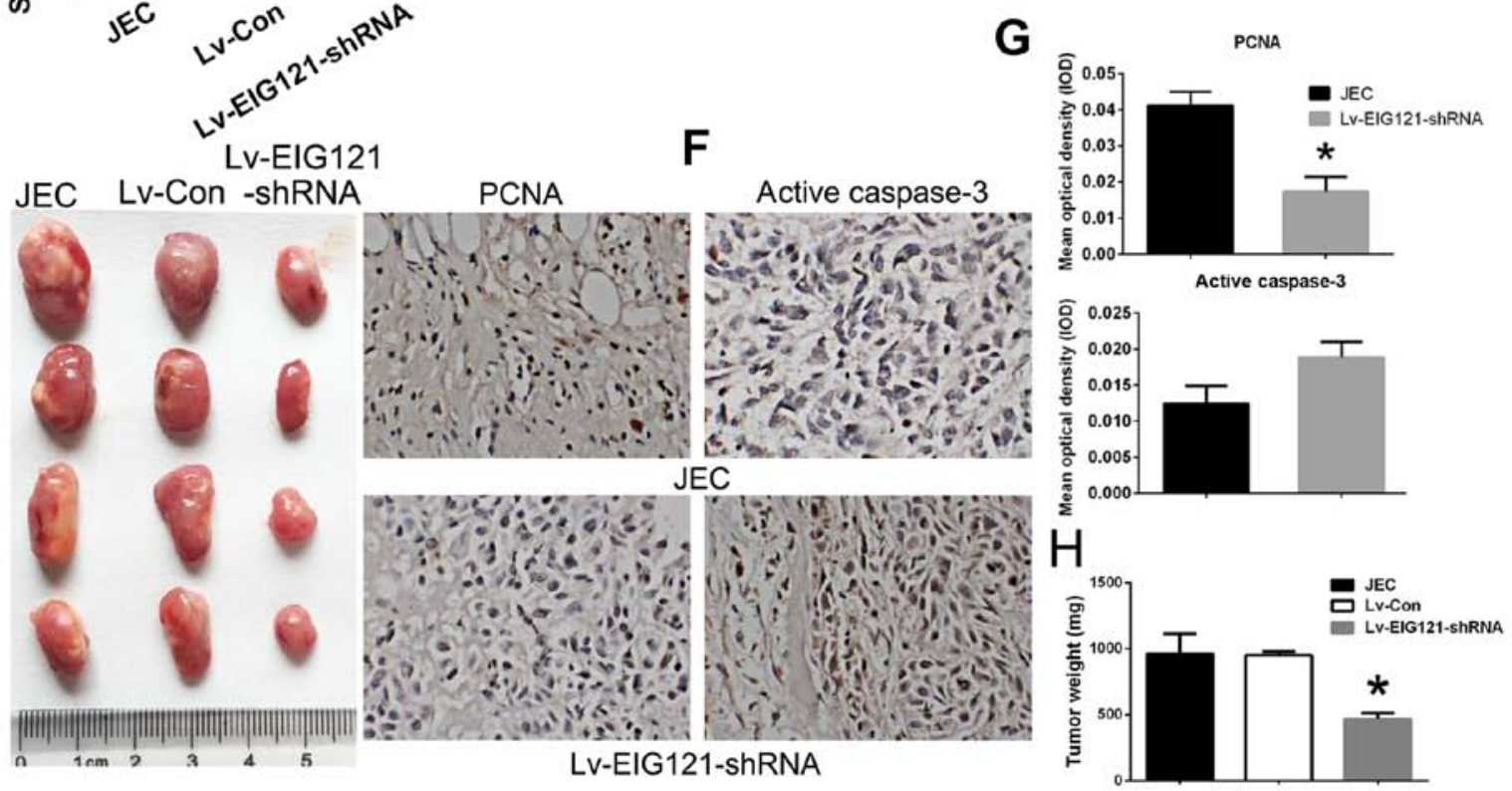

Figure 6. EIG121 knockdown in JEC cells results in stemness reduction. The relative mRNAs levels and protein expression of CSC markers as indicated were determined by QPCR (A) and western blotting (B) respectively. JEC cells were used as control group (Con), "P<0.05 vs. control. Self-renewal efficiency of both sphere number (C) and sphere size (x100 magnification) (D) were determined, JEC cells were used as control group (Con), ${ }^{*} \mathrm{P}<0.05 \mathrm{vs}$. JEC. Lv-Con or Lv-EIG121-shRNA was infected into JEC cells which were injected into the nude mice $(\mathrm{n}=4)$, respectively. Tumors formed in the Lv-EIG121-shRNA group were markedly smaller relative to controls (E). The tumor sections were IHC stained using antibodies against PCNA and active caspase-3 (F) and the optical density was analysed using IPP6.0 (G). Tumor weights are represented as means of tumor weights \pm SD $(\mathrm{H})$. Error bars indicate mean \pm standard errors of the mean. ${ }^{*} \mathrm{P}<0.05$. 
staining and stronger active caspase- 3 staining than that in JEC and Lv-Con cells (Fig. 6F and G). These results indicate that EIG121 knockdown in JEC cells resulted in reduction of stemness and tumorigenesis.

\section{Discussion}

Endometrial cancer is one of the most common gynecologic malignancies. Chemotherapy is the main method of systemic therapy for endometrial cancer (15). Unfortunately, EC is a typical low chemosensitive cancer type. Therefore, exploring the underlying molecular mechanism for the EC chemoresistance is of great importance for novel therapeutic drug exploration. Low chemosensitivity relates to two important mechanisms that might be involved in autophagy and cancer stem cells (CSCs).

CSCs are undifferentiated cells with self-renewal ability that can differentiate into multiple lineages. Once CSCs are forced to differentiate, these cells lose their quiescent properties and become more sensitive to chemotherapy (41). It has been hypothesized that the reason for failure of chemotherapy is due to limited eradication of the CSCs. Mounting evidence reinforced the foundation for emergence of CSC-targeted therapeutic strategies that may help to enhance the efficacy of conventional anticancer therapies (27). The existence of CSCs has been confirmed in different tumor types including EC. CD $133^{+} / \mathrm{CD}_{4} 4^{+}$carcinoma stem cells from human EC cell lines play a crucial role in proliferation, metastasis, recurrence, and development of chemotherapy resistance possessing high proliferation, migration, multidrug resistance and tumorigenic capacity $(42,43)$. In this study, we chose endometrial adenocarcinoma cell line JEC which has low sensitivity to paclitaxel as the parental cells, and $\mathrm{CD} 133^{+} / \mathrm{CD} 44^{+}$cells obtained by microbead sorting were used as ECSCs which were verified using relative expression of stemness marker genes.

ECSCs are thought as plausible root cause of low chemosensitivity in EC, however, the mechanisms are still not understood. Autophagy is a highly regulated conserved catabolic process that functions as a cell survival mechanism during cellular stress such as starvation, hypoxia, and chemo/ radiotherapy (44). Autophagy-mediated stress tolerance can facilitate cell survival by sustaining energy production which could lead to tumor growth and drug resistance (45). Previous studies have shown that autophagy inhibition restored chemosensitivity in various cancer types which consolidated autophagy as a therapeutic target (27).

CSCs are believed to be dependent on their own microenvironment to sustain the population and autophagy has been found as an important mechanism for CSC survival and drug resistance $(25,26)$. Accumulating evidence provides insight into the function of autophagy in CSC maintenance, plasticity and survival (17-19). The autophagy level is higher in CSCs than normal cancer cells and CSCs are more sensitive to autophagy inhibition compared to cells not expressing CSC markers (20). It was demonstrated that autophagy is essential for CSC maintenance. Autophagy enriched the population of colorectal and liver CSCs and participated in maintaining the stemness of colorectal and liver CSCs $(21,22)$. Furthermore, reduced 'stemness' were observed afterCQ-mediated autophagy inhibition in sorted MDA-MB-231 CSCs (19). The increasement of spheres could be reversed by a 3MA treatment (23). Besides, CQ effectively targets CSCs via autophagy inhibition in triple-negative breast cancer (24). These results suggested that autophagy is closely associated with the stemness of CSCs and could be a important mechanism that drives the growth of cancer stem cells.

In our study, we verified enhanced autophagy in $\mathrm{CD} 33^{+} / \mathrm{CD} 44^{+} \mathrm{JEC}$ cells compared with JEC parental cells. Then successive JEC spheroid culture was performed and the relative expression of CSC marker was measured. It was obviously that with the increase of stemness, autophagy also increased gradually. These results confirmed the close relationship between ECSCs and autophagy to some extent. Besides, when the autophagy inhibitors (3-MA and CQ) were added in the successive spheroid culture medium, the self-renewal capacity reduced obviously. It demonstrated that autophagy would partially play a role in stemness-mediation. In addition, autophagy was reported to take part in the maintenance dynamic equilibrium between CSCs and normal cancer cells (28). So we performed phenotypic recovery assay using P3 spheres to detect the re-differentiation ability of JEC spheres.

Remarkably, when the autophagy inhibitor (3-MA or CQ) was added in the normal medium, it was more difficult to restore the adherent growth status of the P3 spheres. This result indicated that when autophagy was repressed, the re-differentiation ability of JEC spheres was reduced which was consistent with the above point of view. When the PTX was used in combination of autophagy inhibitors (3-MA or CQ), the sensitivity of ECSCs was increased significantly. Our data suggest that autophagy in ECSCs help in their survival and inhibition of autophagy can alleviate ECSC resistance to some extent and loss of stemness would mean a decrease in anti-apoptosis capacity. CSCs contain multiple mechanisms to control cell death, which aids to protect these crucial cells from cytotoxic insults. In CSCs, elevated anti-apoptotic protein expression increases the threshold for apoptosis induction and thereby directly protects the cells against apoptosis (46). For example, in breast and AML CSCs, BCL2 and BCLXL are highly expressed $(47,48)$. Besides an elevated apoptotic threshold, CSCs display high expression of drug efflux pumps, such as ATP-binding cassette (ABC) transporter family proteins (49). These proteins are important for efflux of chemotherapy across the plasma membrane. However, a potentially more challenging problem is the recent observation that CSCs may exist that display quiescent properties which could escape classical chemotherapy and subsequently induce re-growth of the tumor (50). Our data establish autophagy as a novel therapeutic target whose modulation presents new opportunities for the low chemosensitivity of EC.

It was previously reported that the novel estrogen-induced gene EIG121, which is overexpressed in endometrial hyperplasia and endometrioid-type endometrial carcinoma, was identified as a important autophagy regulator protecting cells from cell death in EC $(51,52)$. As stated above, we have clarified that autophagy could be one of the important reasons for chemoresistance in ECSCs. Thus, we speculated that as an autophagy regulator of EC, EIG121 played a role in regulation of ECSCs autophagy and EC cell stemness. The lentivirus mediated EIG121 loss-of-function cell models 
were constructed in ECSCs and JEC cells, respectively, and we found EIG121 played an autophagy-induced role in JEC-obtained ECSCs and its knockdown in JEC cells resulted in stemness reduction. The experimental results agreed with our conjecture.

This study also has deficiencies, endometrial carcinoma can be classified into estrogen-dependent type I and -independent type II. In contrast, type II endometrial carcinoma is usually ER-negative, and poorly differentiated, of high grade and poor prognosis which account for $\sim 15 \%$ of cases and responsible for $\sim 50 \%$ of all relapses. Thus, studies targeting ECSCs of type II EC seems more meaningful. CD133+/CD $44^{+}$ carcinoma stem cells from human type II EC cell lines (KLE, AN3CA) have been used in previous research (27). In order to explore the functional role of EIG121 in ECSCs, we finally chose type I EC cell line JEC which has low sensitivity to PTX and is ER-positive to perform our study. As to why EIG121 upregulated in the absence of estrogen, this may be related to its multiple functional roles other than for estrogen induced gene which need further exploration and the relationship between autophagy and stemness alteration in type II EC would be the next research topic.

In conclusion, this study uncovered the close relationship between the regulation of autophagy and stemness in ECSCs for the first time and clarified autophagy played an important role in stemness alteration of ECSCs. Moreover, it was found that EIG121 exerted dual functions in the regulation of autophagy and stemness not only in normal EC cells but also ECSCs. These findings provide useful information for developing targeted therapies for endometrial carcinoma.

\section{References}

1. Siegel R, Naishadham D and Jemal A: Cancer statistics, 2012. CA Cancer J Clin 62: 10-29, 2012.

2. Ushijima K: Current status of gynecologic cancer in Japan. J Gynecol Oncol 20: 67-71, 2009.

3. Takahashi A, Kimura F, Yamanaka A, Takebayashi A, Kita N, Takahashi K and Murakami T: Metformin impairs growth of endometrial cancer cells via cell cycle arrest and concomitant autophagy and apoptosis. Cancer Cell Int 14: 53, 2014.

4. Burke WM, Orr J, Leitao M, Salom E, Gehrig P, Olawaiye AB, Brewer M, Boruta D, Herzog TJ and Shahin FA; SGO Clinical Practice Endometrial Cancer Working Group; Society of Gynecologic Oncology Clinical Practice Committee Endometrial cancer: a review and current management strategies: part II. Gynecol Oncol 134: 393-402, 2014

5. Liu S and Li X: Autophagy inhibition enhances sensitivity of endometrial carcinoma cells to paclitaxel. Int J Oncol 46: 2399-2408, 2015.

6. Wilson TR, Longley DB and Johnston PG: Chemoresistance in solid tumours. Ann Oncol (Suppl) 10: x315-x324, 2006.

7. Ayers D and Nasti A: Utilisation of nanoparticle technology in cancer chemoresistance. J Drug Deliv 2012: 265691, 2012.

8. Carvalho MJ, Laranjo M, Abrantes AM, Torgal I, Botelho MF and Oliveira CF: Clinical translation for endometrial cancer stem cells hypothesis. Cancer Metastasis Rev 34: 401-416, 2015.

9. Visvader JE and Lindeman GJ: Cancer stem cells in solid tumours: Accumulating evidence and unresolved questions. Nat Rev Cancer 8: 755-768, 2008.

10. Friel AM, Sergent PA, Patnaude C, Szotek PP, Oliva E, Scadden DT, Seiden MV, Foster R and Rueda BR: Functional analyses of the cancer stem cell-like properties of human endometrial tumor initiating cells. Cell Cycle 7: 242-249, 2008.

11. Kato K, Takao T, Kuboyama A, Tanaka Y, Ohgami T, Yamaguchi S, Adachi S, Yoneda T, Ueoka Y, Kato K, et al: Endometrial cancer side-population cells show prominent migration and have a potential to differentiate into the mesenchymal cell lineage. Am J Pathol 176: 381-392, 2010.
12. Singh S, Brocker C, Koppaka V, Chen Y, Jackson BC, Matsumoto A, Thompson DC and Vasiliou V: Aldehyde dehydrogenases in cellular responses to oxidative/electrophilic stress. Free Radic Biol Med 56: 89-101, 2013.

13. Tang DG: Understanding cancer stem cell heterogeneity and plasticity. Cell Res 22: 457-472, 2012.

14. Cojoc M, Mäbert K, Muders MH and Dubrovska A: A role for cancer stem cells in therapy resistance: Cellular and molecular mechanisms. Semin Cancer Biol 31: 16-27, 2015.

15. Fukuda T, Oda K, Wada-Hiraike O, Sone K, Inaba K, Ikeda Y, Miyasaka A, Kashiyama T, Tanikawa M, Arimoto T, et al: The anti-malarial chloroquine suppresses proliferation and overcomes cisplatin resistance of endometrial cancer cells via autophagy inhibition. Gynecol Oncol 137: 538-545, 2015.

16. Ran X, Yang J, Liu C, Zhou P, Xiao L and Zhang K: MiR-218 inhibits HMGB1-mediated autophagy in endometrial carcinoma cells during chemotherapy. Int J Clin Exp Pathol 8: 6617-6626, 2015.

17. Lei Y, Zhang D, Yu J, Dong H, Zhang J and Yang S: Targeting autophagy in cancer stem cells as an anticancer therapy. Cancer Lett 393: 33-39, 2017.

18. Sharif T, Martell E, Dai C, Kennedy BE, Murphy P, Clements DR, Kim Y, Lee PW and Gujar SA: Autophagic homeostasis is required for the pluripotency of cancer stem cells. Autophagy 13: 264-284, 2017.

19. Sun R, Shen S, Zhang YJ, Xu CF, Cao ZT, Wen LP and Wang J: Nanoparticle-facilitated autophagy inhibition promotes the efficacy of chemotherapeutics against breast cancer stem cells. Biomaterials 103: 44-55, 2016.

20. Pellegrini P,DyczynskiM,SbranaFV,Karlgren M,BuoncervelloM, Hägg-Olofsson M, Ma R, Hartman J, Bajalica-Lagercrantz S, Grander D, et al: Tumor acidosis enhances cytotoxic effects and autophagy inhibition by salinomycin on cancer cell lines and cancer stem cells. Oncotarget 7: 35703-35723, 2016.

21. Song YJ, Zhang SS, Guo XL, Sun K, Han ZP, Li R, Zhao QD, Deng WJ, Xie XQ, Zhang JW, et al: Autophagy contributes to the survival of $\mathrm{CD}_{133^{+}}$liver cancer stem cells in the hypoxic and nutrient-deprived tumor microenvironment. Cancer Lett 339: 70-81, 2013.

22. Yang HZ, Ma Y, Zhou Y, Xu LM, Chen XJ, Ding WB and Zou HB: Autophagy contributes to the enrichment and survival of colorectal cancer stem cells under oxaliplatin treatment. Cancer Lett 361: 128-136, 2015.

23. Berardi DE, Flumian C, Rodriguez CE, Bessone MI, Cirigliano SM, Joffé ED, Fiszman GL, Urtreger AJ and Todaro LB: PKCס inhibition impairs mammary cancer proliferative capacity but selects cancer stem cells, involving autophagy. J Cell Biochem 117: 730-740, 2016.

24. Liang DH, Choi DS, Ensor JE, Kaipparettu BA, Bass BL and Chang JC: The autophagy inhibitor chloroquine targets cancer stem cells in triple-negative breast cancer by inducing mitochondrial damage and impairing DNA break repair. Cancer Lett 376: 249-258, 2016.

25. Bellodi C, Lidonnici MR, Hamilton A, Helgason GV, Soliera AR, Ronchetti M, Galavotti S, Young KW, Selmi T, Yacobi R, et al: Targeting autophagy potentiates tyrosine kinase inhibitor-induced cell death in Philadelphia chromosome-positive cells, including primary CML stem cells. J Clin Invest 119: 1109-1123, 2009.

26. Jiang H, Gomez-Manzano C, Aoki H, Alonso MM, Kondo S, McCormick F, Xu J, Kondo Y, Bekele BN, Colman H, et al: Examination of the therapeutic potential of Delta-24-RGD in brain tumor stem cells: Role of autophagic cell death. J Natl Cancer Inst 99: 1410-1414, 2007.

27. Ojha R, Bhattacharyya S and Singh SK: Autophagy in cancer stem cells: A potential link between chemoresistance, recurrence, and metastasis. Biores Open Access 4: 97-108, 2015.

28. Zhu H, Wang D, Liu Y, Su Z, Zhang L, Chen F, Zhou Y, Wu Y, Yu M, Zhang Z, et al: Role of the hypoxia-inducible factor-1 alpha induced autophagy in the conversion of non-stem pancreatic cancer cells into $\mathrm{CD} 133^{+}$pancreatic cancer stem-like cells. Cancer Cell Int 13: 119, 2013.

29. Chen Z, Che Q, He X, Wang F, Wang H, Zhu M, Sun J and Wan X: Stem cell protein Piwill endowed endometrial cancer cells with stem-like properties via inducing epithelial-mesenchymal transition. BMC Cancer 15: 811, 2015.

30. Ciavardelli D, Rossi C, Barcaroli D, Volpe S, Consalvo A, Zucchelli M, De Cola A, Scavo E, Carollo R, D'Agostino D, et al: Breast cancer stem cells rely on fermentative glycolysis and are sensitive to 2-deoxyglucose treatment. Cell Death Dis 5: e1336, 2014. 
31. van der Zee M, Sacchetti A, Cansoy M, Joosten R, Teeuwssen M, Heijmans-Antonissen C, Ewing-Graham PC, Burger CW, Blok LJ and Fodde R: IL6/JAK1/STAT3 signaling blockade in endometrial cancer affects the ALDHhi/CD126 ${ }^{+}$stem-like component and reduces tumor burden. Cancer Res 75: 3608-3622, 2015.

32. Yang L and Lai D: Ovarian cancer stem cells enrichment. Methods Mol Biol 1049: 337-345, 2013.

33. Zhong Y, Guan K, Guo S, Zhou C, Wang D, Ma W, Zhang Y, Li C and Zhang S: Spheres derived from the human SK-RC-42 renal cell carcinoma cell line are enriched in cancer stem cells. Cancer Lett 299: 150-160, 2010.

34. Liao WT, Wang X, Xu LH, Kong QL, Yu CP, Li MZ, Shi L, Zeng MS and Song LB: Centromere protein $\mathrm{H}$ is a novel prognostic marker for human nonsmall cell lung cancer progression and overall patient survival. Cancer 115: 1507-1517, 2009.

35. Elbasateeny SS, Salem AA, Abdelsalam WA and Salem RA: Immunohistochemical expression of cancer stem cell related markers CD44 and CD133 in endometrial cancer. Pathol Res Pract 212: 10-16, 2016.

36. Kato K: Endometrial cancer stem cells: A new target for cancer therapy. Anticancer Res 32: 2283-2293, 2012.

37. Kyo $\mathrm{S}$ and Kato K: Endometrial cancer stem cell as a potential therapeutic target. Semin Reprod Med 33: 341-349, 2015.

38. Gao Y, Liu T and Huang Y: MicroRNA-134 suppresses endometrial cancer stem cells by targeting POGLUT1 and Notch pathway proteins. FEBS Lett 589: 207-214, 2015.

39. Siegel R, Naishadham D and Jemal A: Cancer statistics for Hispanics/Latinos, 2012. CA Cancer J Clin 62: 283-298, 2012

40. Siegel R, DeSantis C, Virgo K, Stein K, Mariotto A, Smith T, Cooper D, Gansler T, Lerro C, Fedewa S, et al: Cancer treatment and survivorship statistics, 2012. CA Cancer J Clin 62: 220-241, 2012.

41. Gómez-López S, Lerner RG and Petritsch C: Asymmetric cell division of stem and progenitor cells during homeostasis and cancer. Cell Mol Life Sci 71: 575-597, 2014.

42. Gehrig PA and Bae-Jump VL: Promising novel therapies for the treatment of endometrial cancer. Gynecol Oncol 116: 187-194, 2010.
43. Jiang F, Liu T, He Y, Yan Q, Chen X, Wang H and Wan X: MiR-125b promotes proliferation and migration of type II endometrial carcinoma cells through targeting TP53INP1 tumor suppressor in vitro and in vivo. BMC Cancer 11: 425, 2011.

44. Sui X, Chen R, Wang Z, Huang Z, Kong N, Zhang M, Han W, Lou F, Yang J, Zhang Q, et al: Autophagy and chemotherapy resistance: A promising therapeutic target for cancer treatment. Cell Death Dis 4: e838, 2013.

45. Nagelkerke A, Sweep FC, Geurts-Moespot A, Bussink J and Span PN: Therapeutic targeting of autophagy in cancer. Part I: Molecular pathways controlling autophagy. Semin Cancer Biol 31: 89-98, 2015.

46. Colak S and Medema JP: Cancer stem cells - important players in tumor therapy resistance. FEBS J 281: 4779-4791, 2014.

47. Konopleva M, Zhao S, Hu W, Jiang S, Snell V, Weidner D, Jackson CE, Zhang X, Champlin R, Estey E, et al: The antiapoptotic genes $\mathrm{Bcl}-\mathrm{X}(\mathrm{L})$ and $\mathrm{Bcl}-2$ are over-expressed and contribute to chemoresistance of non-proliferating leukaemic CD34 ${ }^{+}$cells. Br J Haematol 118: 521-534, 2002.

48. Madjd Z, Mehrjerdi AZ, Sharifi AM, Molanaei S, Shahzadi SZ and Asadi-Lari M: CD44 ${ }^{+}$cancer cells express higher levels of the anti-apoptotic protein Bcl-2 in breast tumours. Cancer Immun 9: 4, 2009.

49. Wilson BJ, Schatton T, Zhan Q, Gasser M, Ma J, Saab KR, Schanche R, Waaga-Gasser AM, Gold JS, Huang Q, et al: ABCB5 identifies a therapy-refractory tumor cell population in colorectal cancer patients. Cancer Res 71: 5307-5316, 2011.

50. Gao MQ, Choi YP, Kang S, Youn JH and Cho NH: CD24+ cells from hierarchically organized ovarian cancer are enriched in cancer stem cells. Oncogene 29: 2672-2680, 2010.

51. Deng L, Broaddus RR, McCampbell A,, Shipley GL, Loose DS, Stancel GM, Pickar JH and Davies PJ: Identification of a novel estrogen-regulated gene, EIG121, induced by hormone replacement therapy and differentially expressed in type I and type II endometrial cancer. Clin Cancer Res 11: 8258-8264, 2005

52. Deng L, Feng J and Broaddus RR: The novel estrogen-induced gene EIG121 regulates autophagy and promotes cell survival under stress. Cell Death Dis 1: e32, 2010. 